\title{
More-than-Human Politics: The Case of Plastic Bags
}

\section{Gay Hawkins}

Suddenly everyone is talking about plastic bags. The muted chatter that has surrounded them for years has become loud and insistent. Open any newspaper around Australia and you are confronted with headlines like: The Battle of the Bag, Eco Worriers - How Buying the Groceries Presents Environmental Dilemmas, Ban on Bags Can't Carry Weight, or Plastic Bags - the Cane Toads of Capitalism! As this publicity shows bags have changed, they've become contested matter, a site of controversy over their uses and impacts. As scientists discover marine life choking on bags and environmental activists document their endless afterlife in landfill, they have been transformed from innocuous disposable container to dangerous threat to the environment.

But what of the bag in all this? Even though it seems to be the centre of attention it remains strangely mute and submissive, a passive victim of reclassification. Humans gather around it disputing competing evidence of its impacts, arguing over which facts are true. The bag is definitely a problem but it is not a political actor. In seeking to address plastic bags' stubborn materiality the political action seems to flow all one way. Scientific knowledge and environmental education frame the bag as a bad object to be rejected by the environmentally responsible human subject.

This mode of political analysis gives excessive primacy to humans and the subject object distinction. The only power the bag seems to have is to remind humans of their political agency, to confirm their capacity to act on a world of objects and nonhuman stuff out there, to say NO to plastic bags! Rejection and refusal become the other side of neoliberalism's valorisation of choice. The freedom to choose, that gesture so fundamental to the formation of the neoliberal subject, is also the freedom not to choose. In this valorisation of voluntarism things matter only because they reveal human will and mastery. Whether selected or rejected, objects are in the service of a political hierarchy in which subjects rule.

But what if we understood subjects and objects not as fixed oppositions but products of their relating, as co-constituted with multiple social and material reverberations? What would it mean for political analysis if the starting point for investigation was the role of nonhuman entities in assembling distinct social connections? How would the politics of plastic bags be understood if the focus shifted from questions of effects to questions of practice? From predetermined environmental impacts to the various ways in which plastic materiality becomes 
entangled with publics and citizenship? What is the potency of these objects in various forms of everyday conduct and political association? How can we make sense of plastic bags as the stuff of politics?

These are the questions that drive this paper. My broad aim is to show why socio-ecological humanities research needs to pay more attention to questions of matter, and to argue that nonhuman entities are now central participants in many political processes. Matter doesn't simply challenge the anthropocentrism of much political thinking, it also reminds us of how many contemporary political disputes now involve the management and regulation of the nonhuman, generating increasing crossovers between the political, the scientific, the technical and the ethical.

My primary concern is how to think through the relations between politics, plastic and social life in more productive ways. If we know plastics as waste are bad - and there are many different registers of bad here - how might we shift political analysis from this statement of fact and its depressing effects to an engagement with new possibilities, new forms of association around plastics and the political? What forces and thinking are needed to create different political and environmental realities, and what role would we give to plastic bags in this process? How could we create a more than human politics around plastic: a political collectivity or public that recognised plastic bags' capacity to suggest more ecologically careful modes of living?

In posing these questions I am explicitly writing against certain versions of environmentalism. Rather than focus on deep ecology's emphasis on transpersonal connections with nature as the motivation for action, I want to investigate how everyday matter gets implicated in political disputes and ethical practices. Say No to Plastic Bags campaigns are a good example of this. While saving 'nature' or 'the environment' may be the backdrop to these campaigns: abstract idealised spaces called up as rationales for ethical practice, the real political action is in ordinary habits of shopping. What the shopper puts their purchases in and how these choices come to be seen as evidence of an ethical sensibility. This is 'environmental ethics' not as interconnectivity with nature but as ubiquitous, historically conditioned, material practices that organise distinct conducts and forms of reasoning. The question is: what is the role of the plastic bag in these conducts?

This is a provocative question for much environmental ethics. While this diverse field has been crucial in arguing for the ineluctable connections that bind humans, animals, ecosystems and so on, there has been a certain reluctance to acknowledge the ethical significance of bad stuff in the environment. Oceans streaked with sewage, rivers choked with plastic bags, landfills full of discarded computers are seen as outside an ethics and politics attuned to interconnectivity. This destructive matter is seen as disrupting the deep ecological impulse to 
identify with nature. While the affective horror of dangerous matter is acknowledged, particularly its capacity to trigger grief or despair for a contaminated world, there is a certain unwillingness to comprehend how bad stuff comes to matter phenomenologically and politically, in and of itself. How this material becomes implicated in the organization of distinct regimes of living and forms of ethical action or blindness. The tendency is to reduce it to a negative force obliterating the rights of nature, yet more evidence of human mastery and exploitation.

In many versions of environmental ethics destructive matter manifests what Noel Castree describes as a 'materialist essentialism'. It is seen as having clearly definable properties that are ontologically fixed. And, as Castree explains, 'these properties can, in the final instance, be appealed to by environmental ethicists (explicitly or implicitly) to anchor claims about the who, what and how of ethical considerability' (8). Despite the recognition of relational ontologies and differences-within-connections, the tendency is to demonise environmentally dangerous matter as materially irreducible. This inevitably privileges humans as the source of ethical awareness and action. While natural matter is recognised as ethically significant and as a site of communicative vitality, destructive artificial material is afforded no such capacity. Humans are not invited to be open to its wilful forces rather, they are urged to enact their ethical will and eliminate it.

This is how ethics slides into moralism. As much as one may agree that the world would be a better place without plastic bags, the moral imperative to refuse them denies the complexity of contexts in which we encounter them and the diversity of responses bags generate. It fixes the material qualities of plastic bags and human responses to them. Approaches to environmental ethics that invoke material essentialism deny the contingency of ethical constituencies and relations. They can also deny the affective dimensions of ethics, the ways in which corporeal interactions with the world are always mixed up with ethical reasoning and negotiations. There is no possibility that plastic bags might move us or enchant us or invite simple gratitude for their mundane convenience; that they might prompt us to behave differently.

The first step in a more-than-human politics, then, is to examine how plastic bags come to matter without recourse to a materialist essentialism, and without putting humans at the centre of the story. By letting plastic bags 'have their say' or, as Karen Barad would say, allowing 'matter its due as an active participant in the world's becoming' (803), it is possible to open up a different line of thinking about the relations between ethics, politics and the environment. One that begins from the modest recognition of plastic bags not as phobic objects ruining nature but as things we are caught up with: things that are materialized or dematerialized through diverse habits and associations. By refusing to situate 
plastic bags in a moral framework, as always already bad, their materiality becomes more contingent and more active. Bags cease to be only ever passive and polluting and become, instead, active participants in various everyday practices in which the materiality and meaning of both bodies and bags are fashioned. This is not to say that materiality is reducible to relations. Rather, that different interactions make present different material qualities and affects. And it is this contestability of matter that is fundamentally implicated in ethico-political deliberations. The challenge is to understand the ways in which various plastic materialities become manifest and the impacts of these materialities. How might they generate political capabilities for plastic bags, and how might these capabilities reverberate on bodies, on habits, and on enhanced ecological awareness?

Central to this approach is an account of agency that is cut loose from a traditional humanist orbit. As Barad says:

Agency is not aligned with human intentionality or subjectivity... Agency is a matter of intra-acting, it is an enactment, not something that someone or something has. Agency cannot be designated as an attribute of 'subjects' or 'objects' (as they do not preexist as such). Agency is not an attribute whatsoever - it is 'doing'/'being' in its intra-activity. Agency is the enactment of iterative changes to particular practices through the dynamics of intra-activity. Agency is about the possibilities and accountability entailed in reconfiguring material-discursive apparatuses of bodily production... Particular possibilities for acting exist at every moment, and these changing possibilities entail a responsibility to intervene in the world's becoming, to contest and rework what matters and what is excluded from mattering. (826-27)

This echoes Jane Bennett's description of agency as the 'differentially distributed capacity to make a difference in the world' ('Force of Things' 355). What both these thinkers force us to acknowledge is the capacity of plastic bags, in certain arrangements, to enact iterative changes, to a make a difference. The question is in what senses do these changes inaugurate a more-than-human politics?

\section{Plastic bags in action}

To pursue these issues let's consider two plastic bags in action: the banned plastic bag of Say No campaigns and some abandoned plastic bags that are the central characters in a recent Adidas ad. Each of these bags manifest distinct plastic materialities and each generate different affective energies. While they share the same material qualities, the performance of these qualities in different assemblages is evidence that plastic materiality cannot be essentialised, and nor can ethics. Rather than being a set of fixed principles in the name of moral reason, what these plastic bags reveal is the fundamental porousness and instability of 
ethics. In these examples ethics emerge as ubiquitous, affective and thoroughly imbricated with corporeality. Acknowledging this ethical instability does not mean an abandonment of environmental politics, it means a different mode of political thinking, less concerned with dissensus and contestation and more concerned with speculative practices and improvisation. These plastic bags 'force thought', to use Isabelle Stengers' phrase. They make themselves known in different ways and in being open to these different knowledges it may be possible to enlarge the politics of plastic bags, to imagine different modes of thinking, feeling and acting with them.

\section{Say No!}

Campaigns to eliminate plastic bags have become a common fixture in countries where environmentalism is highly organised. Sometimes run by governments, sometimes by green or activist organizations, these campaigns focus on reducing plastic bag use by urging consumers to choose more sustainable alternatives. In Australia that alternative is, most often, a green shopping bag made out of long lasting polypropylene with an environmental slogan on the side. In encouraging shoppers to voluntarily reject disposable plastic bags Say No campaigns are explicitly pedagogic, their intent is to reform populations and change everyday habits. But how do they do this and what is the role of the plastic bag in this process? By investigating how environmental campaigns problematise plastic bags and shopping practices it is possible to see how these mundane objects become caught up in new associations that organise a distinct set of interfaces between bodily habits, materiality and ethical reasoning. How, in activating techniques of conscience, plastic bags participate in fashioning an environmentally concerned shopper.

Using a range of scientific information about environmental impacts Say No campaigns frame plastic bags as hazardous. And, in the same moment, they invite shoppers to engage in self-scrutiny and reflect on their everyday conducts around them. This framing is explicitly moral. It involves fixed oppositions such as environmentally friendly/environmentally hazardous, and it appeals to categorical imperatives such as protecting nature or global ecological survival. This is the larger scale in which minor habits and their impacts are situated. In constituting plastic bags as a 'matter of concern', as Bruno Latour might say, Say No campaigns activate specific aspects of the materiality of the plastic bag: their slow process of decomposition, their tendency to trap or choke marine animals, their oppressive ubiquity. These material qualities are not representations or social constructions they are a particular aspect of plastic materiality that is made present in order to transform the meaning of the bag from innocuous container to polluting and recalcitrant matter. These reframings of the bag expose its material afterlife and extend the ethical imagination of the shopper. They reveal 'disposability' as a myth, and establish a network of 
connections and obligations between ordinary habits and the purity and otherness of nature. In this way the bag becomes capable of generating not only environmental concern but also guilt.

Guilt is a powerful reminder of the claims matter can make on us. Adopting new conducts that avoid plastic bags involves an acceptance of plastic materiality as dangerous, and a willingness to change one's relationship to that matter out of a sense of obligation to the environment. This new network of relations between bags, shoppers and nature involves practices of self-monitoring and discipline that Ian Hunter describes as 'techniques of conscience' (128). The capacity of plastic bags to make some shoppers hesitate before they reach for one is only successful if subjects are receptive to the ethical obligations the bag's materiality poses to them, if they have a conscience.

According to Foucault conscience is a product of a range of techniques of the self that have come to constitute distinct styles of subjectivity (29-30). To be a subject now means cultivating particular modes of reflexivity. It means developing special ethical techniques and capacities. These techniques and capacities are historically variable in their form and targets. Their presence is not evidence of a foundational interiority grounding the subject, rather, of shifting regimes of living and self-cultivation. Techniques of conscience make the self into an object of ethical attention; they show how subjects problematize and modify their conduct on the basis of ethical principles to which they aspire. And, as Say No campaigns reveal, matter can play a key role in activating techniques of conscience.

While environmental education campaigns, and their psychological logics, assume that ethical agency resides in the raised consciousness or 'awareness' of the concerned individual, that individual is contextually situated. And those contexts involve multiple interactions with plastic materiality. Public campaigns about the hazardous materiality of plastic bags are successful not simply because they have re-educated shoppers but because they have animated the materiality of bags in powerful ways. They have made the plastic bag a potent intermediary between an interior reception of an ethical command and the mobilization of the will to abide by it (Bennett, Enchantment 156).

Say No campaigns run by governments or environmental NGOs show how plastic bags have become implicated in processes of moral self-regulation and conscience, how circuits of guilt, self-reproach and virtue have become enfolded with ordinary acts of shopping. And how, in activating techniques of conscience, the plastic bag participates in shaping an environmentally aware subject. The force of matter in this process, its capacity to prompt certain practices in particular arrangements, is evidence of the formation of a distinct ethical constituency in which changed interactions between bags and bodies produce new effects. These effects are more than just reduction in use they also involve the formation of 
collectivities. For the shopper, recognition of bags' polluting materiality is a source of ethical concern and a prompt to reject them. When that shopper arrives at the supermarket check out and presents their green eco bags, the absence of the plastic bag is a public declaration of environmental awareness. The eco bag as an accessory becomes a marker of a nascent political community of concerned subjects whose collective rejection of plastic bags implicitly links them. In the same way, the shopper struggling across the car park arms weighed down with full plastic bags is vulnerable to public scorn about their bad habits. How many times at the checkout have we heard a shopper declare guiltily: 'sorry, I forgot to bring my green bags'.

There is no question that Say No campaigns involve differential degrees of agency on the part of plastic materiality. That the ethical constituency formed through these campaigns is an environmentally aware subject who encounters the bag as hazardous matter. And that those who continue to use plastic bags in a context of environmental campaigns against them can feel exposed or uneasy. There is also no question that the affective energies that are generated by this style of environmental campaign involve various registers of moral righteousness and anxiety. However, as effective as these campaigns have been in some places in reducing use and developing enhanced ecological awareness, their limits must also be acknowledged.

William Connolly argues that conscience and other code driven moral techniques are crude and blunt tools for coping with the world. Their tendency to ground moral or political actions in law, God, global survival, consensus or any other categorical imperative makes them blind to the ambiguous and disturbing aspects of many encounters. The moral weight of codes can too easily turn obligation into duty, guilt and resentment: 'I should do this ... because the environment is suffering, because I am law abiding, because I am virtuous' (195). This is obligation working in the interests of human mastery and self-certainty, obligation that implicitly maintains the stability of being. While Say No campaigns have only been successful because they have animated the materiality of bags and implicated humans in new relations with them, the differential agency of the bag in this process is disavowed. It is something to be controlled by human will, not a participant in an emergent ethical constituency. The logic of categorical imperatives and prohibition privileges the concerned and virtuous shopper as the source of ethical action and change. In this way, obligation and guilt suppress the agency of the bag and deny the ways in which its materiality always exceeds moral framings.

\section{Adidas and the plastic bag soccer ball}

In my next example I am going to use an Adidas advertisement to explore a very different instance of how the matter of plastic bags comes to matter. In this example I focus on the performative dimensions of the bag rather than a 
representational or ideological reading of the advertisement. In other words, I want to put aside issues of correspondence or mystification between the audiovisual text and reality. This habit of thinking privileges singular meaning over social and material complexity, and can deny the ways in which representations are simply one of a multiplicity of realities that are all real enough. While there is no question that the aesthetic and economic techniques of advertising and branding are the context for the performance of this particular plastic bag, and that they generate a distinct set of meanings for it, these meanings overlap with and interfere with other realities. As Annemarie Mol would say, reality is always performed and the challenge is to understand how multiple realities involve varieties of truths that are in play with each other. This challenge is both analytical and political. The issue is not about which performance gets closest to the truth of reality but how do some realities come to be more real than others. This is the crux of Mol's account of ontological politics and it resonates with my argument for including the more-than-human in political process. Like Mol, I am concerned with how the various realities of objects get enacted in different settings and how these enactments might suggest different, and perhaps better, modes of living.

My interest in this advertisement, then, concerns the way in which it captures a very different socio-material network between bodies and bags. Unlike Say No campaigns, these plastic bags are not moralised intermediaries prompting techniques of conscience. Rather, they are a practical resource for invention and innovation. The reality they perform resonates with everyday experiences of plastic bags: their mundane convenience, their light and malleable form, their sticky persistence. Of course the material qualities of the bag and the narrative that unfolds around them are generating value and qualities for the brand-Adidas - nothing is impossible! But there is more than a brand being enacted here. There is also another way of relating to matter that is attentive, creative and experimental. The question is: can these bags be considered as implicated in a more-than-human politics and, if so, what kind?

In a recent Adidas ad a small boy roams through an unidentified South American slum collecting plastic bags. He pulls them out of garbage bins, he grabs them blowing about in the wind, there's no question he is on a mission to collect as many bags as possible. Finally, we see him crawl through a fence into an open space and begin fashioning something out of all his bags. It's a soccer ball made by bundling bag after bag into a sphere. As he kicks his plastic bag creation triumphantly into the air the Adidas logo comes up with the slogan-'nothing is impossible'.

The narrative interest in this ad is not simply why is he collecting all these bags but look at what those bags make the boy do. The one blowing down the street just above his head forces him to jump high and grab it before it flies out of 
reach. The one stuck in the barbed wire fence fiercely resists being pulled out; the one in the gutter is sticky with waste. Behind the pulsating Latino sound track we hear the sounds of plastic materiality, their distinctive rustle as they are blown about or pulled. Finally, we see their material malleability, their capacity to be pushed and crammed into all sorts of shapes. Plastic bags are central characters in this ad, they are fundamental to the action. The audience is captured by the performance of their materiality, all the things they can do.

These bags present their materiality as something to be experienced and negotiated. They continually invite the little boy to be patient and persistent, to adapt his actions to the demands of plastic matter. In seeking to create something with the bags the boy has to engage in a collaborative process in which the meaning and materiality of the human and the bag shift. In this advertisement the bag's plastic presence is noticed, not as a bad matter but as what John Law calls 'in-here enactment' (84). For Law, this means the processes whereby material presence is enacted into being in distinct relations and practices. Presence is what is made present in particular relations. However, it also, at the same time, involves manifest absence because presence is always incomplete, always limited and contestable. The manifest absence in this encounter is the moralised plastic bag of environmental awareness and the virtuous identity of the ethical consumer. In this advertisement, the in-here enactment of the bag generates experiential networks of collaboration that disturb neat oppositions between environmentally aware subject and hated object. The plastic bag has become a player in a different reality; in asserting its material presence it disrupts framings of it as dangerous and destructive. Its creative possibilities disrupt the circuits of guilt and conscience that drive moral responses. Instead, the in-here enactment of the bag reveals a different plastic materiality that rearranges conducts and perceptions. As the boy responds to the invitation from the bag to be patient, arrogant senses of human agency and mastery are disrupted. This inanimate thing is animate: it is suggesting particular actions.

The reality that these bags perform reveals their capacity as both practical resources for being and active material force. Humans do things with them, leave their traces on them but this does not mean that they are completely subordinate to human action. They have a 'life' of their own that we have to accommodate in our activities. These bags put questions of action and practice at the centre of ontology, what we can do with them and what they do to us becomes central to how we know them. By insisting that humans work with them, these bags make us aware of the ambiguity of intercorporeality and our complex entanglements with matter. The need for co-operation short circuits guilt and makes humans open to the thing-power potentiality of plastic materiality. These bags are not inert environmental hazards nor are they appealing to conscience. They don't problematise nature or bad habits, they simply make us aware of how plastic bags can be both resistant and useful. This advertisement is a 
powerful reminder that there are multiple realities for plastic bags and, in simply acknowledging this, the moral singularity of Say No campaigns is rendered unstable.

Paul Carter's concept of 'material thinking' is a useful way of making sense of this example. This concept recognises the activity of matter and foregrounds the active role of materiality in thinking and invention. It also seeks to capture the qualitative or phenomenal dimension of things as they are apprehended, as they make themselves noticed, as they bite back. Material thinking works to 'intensify what already exists' (8), as Carter says, and in this intensification we notice materiality in ways that we are often blind to; we respond in ways that involve what Nigel Thrift calls 'processual sensualism', or active ongoing collaboration with the world. I like the way these concepts don't over reach, they don't read into the bag all sorts of social ills. In both Thrift and Carter's paradigm material thinking is not representational thinking - the bag doesn't stand for something else, the evils of a global multinational or child poverty - it is a concept that foregrounds a materialist phenomenology and the ways humans are always entangled with nonhuman entities.

In this way the plastic bag soccer ball suggests a different kind of more-than-human politics; one not based on moral problematisation, ideological critique or human mastery (say no!) but on innovation and invention. This resonates with Deleuze and Parnet's understanding of politics as a process of 'active experimentation.' When matter disturbs and defamiliarises it makes trouble for previous ways of understanding and acting. It can also create spaces of possibility where the immanence of politics as other ways of being is revealed. In the shift from prohibition to experimentation the scale of politics is also transformed. Experimental practices are played out in between large-scale macropolitical institutions and processes and the sub-institutional movements of affect, habit and minor material practices. Central, here, are the ways in which matter can disrupt normativity and moral codes and reveal other affordances and realities. For it is precisely in these minor practices, like being responsive to the plastic bag suggesting that you jump high, that bags can shift perception and suggest experiments with new practices, or make us think again about our relations with them. This ad beautifully captures the collaborative work and imagination involved in creative reuse.

This focus on the performativity of the plastic bag, and the material thinking it generates, could be seen as a refusal of politics, a denial of the ways in which the bag is being used to constitute brand value for a global corporation. In this framework the plastic bag is simply a ruse for the promotion of Adidas as a caring company concerned about poverty and the struggle to overcome immense odds: nothing is impossible. The celebration of the plastic bag soccer ball implicitly invokes conservative ideologies about the dignity of deprivation. There is no 
doubt that the logic of branding is at work here and that the function of the advertisement is to establish the qualitative possibilities of the abstract logo and the commodities attached to it. And, as with all brands, this process reveals some aspects of the commodity but keeps others very well hidden, specifically, the exploitative conditions under which those commodities come into being (Lury 50). As Arvidsson argues brand management is about the 'reflexive filtering of the productivity of the multitude and its re-insertion in the social as a polished quality' (130). The bag is doing this semiotic work but reducing it to just a representation that masks the macropolitics of exploitation imposes a singular material reality on the bag. It simply becomes a surface on which politics is inscribed.

A materialist analysis acknowledges that other realities are present for the bag beyond the symbolic. And that these filter into the advertisement in ways that exceed the controlled realities of 'brand management.' In arguing for a more-than-human politics my aim is not to debunk the advertisement and expose the true meaning of the bag in Adidas' global intentions. Rather, my approach provides evidence of a different set of empirical facts about plastic materiality, that both resonate with everyday encounters and suggest alternative responses to them beyond a moralised environmental politics of prohibition. This insistence on the capacity of the bag to exceed its semiotic and symbolic determinations, to shock and surprise, echoes my claim that the power of the Adidas advertisement lies in its capacity to reveal the material presence of plastic bags not as environmental hazards but as vital matter. We are invited to see them as a creative resource, as a tool for material thinking and, in this moment, the bag becomes a collaborator not a demonised bad thing.

\section{Conclusion}

Different bags, and different performances of plastic materiality made present in different associations. My aim has been to show how bags participate in politics via their capacity for differentially distributed agency. While environmental campaigns have been phenomenally successful in prompting changed habits, it's wrong to think this activity is an exclusive result of a raised human awareness about 'nature' under threat. Nature may be the wider backdrop here but plastic bags are the real stuff of politics. Their capacity to activate techniques of conscience and become ethical intermediaries capable of prompting new human habits makes them potent participants in better practices. In Say No campaigns bags become capable of making claims on humans, of capturing them in experiential networks of obligation that invite them to consider what they do.

However, in Say No campaigns bags can only ever be bad, that is the only aspect of their various material realities that is made present. But bags are also useful and sensual and vital, and they can suggest and invite other sorts of collaboration, 
as the Adidas advertisement shows. And in these relations, unexpected reactions and innovations with matter might surface that generate different circuits of obligation from creative reuse to a deeper ecological thinking about stuff and where it ends up. This is more-than-human politics as active experimentation.

Gay Hawkins is a Professor of media and social theory in the School of English, Media and Performing Arts at UNSW. Her latest books are The Ethics of Waste: How We Relate to Rubbish (2006) and, with Ien Ang and Lamia Dabboussy, The SBS Story: The Challenge of Cultural Diversity (2008). She is currently undertaking a large ARC project, 'From the Tap to the Bottle: The Social and Material Life of Bottled Water'.

\section{Works Cited}

Arvidsson, Adam. Brands: Meaning and Value in Media Culture. London: Routledge, 2006.

Barad, Karen. 'Posthumanist Performativity: Toward an Understanding of How Matter Comes to Matter.' Signs: Journal of Women in Culture and Society 23.1 (2003): 801-31.

Bennett, Jane. The Enchantment of Modern Life. Princeton: Princeton UP, 2001. -, 'The Force of Things: Steps toward an Ecology of Matter.' Political Theory 32.3 (2004): 347-72.

Carter, Paul. Material Thinking. Melbourne: Melbourne UP, 2004.

Castree, Noel. 'A Post-Environmental Ethics.' Ethics, Place and Environment 6.1 (2003): 3-12.

Connolly, William. Why I am Not a Secularist. Minneapolis: U of Minnesota P, 1999.

Deleuze, Gilles and Claire Parnet. Dialogues II. Trans H. Tomlinson and B. Habberjam. London: Continuum, 1987.

Foucault, Michel. The Use of Pleasure. Trans R. Hurley. New York: Vintage, 1985.

Hunter, Ian. 'Subjectivity and Government.' Economy and Society 22. 1 (1993): 123-34.

Latour, Bruno. 'From Realpolitk to Dingpolitik - or how to make things public.' Making Things Public: Atmospheres of Democracy. Ed. Bruno Latour and Paul Weibel. Cambridge, Mass: ZKM and MIT Press, 2005. 14-41.

Law, John. After Method. London: Routledge, 2004. 
Lury, Celia. Brands: The Logos of the Global Economy. London: Routledge, 2004. Mol, Annemarie. The Body Multiple: Ontology in Medical Practice. Durham: Duke, 2002.

Stengers, Isabelle. 'The Cosmopolitcal Proposal.' Making Things Public: Atmospheres of Democracy. Ed. Bruno Latour and Paul Weibel. Cambridge, Mass: ZKM and MIT Press, 2005. 994-1003.

Thrift, Nigel. Non-Representational Theory. London: Routledge, 2008. 